\title{
MANAGEMENT PRACTICES AFFECTING CALVES WELFARE ON FARMS IN SLOVENIA
}

\author{
Jožica Ježek¹, Petra Grabnar², Barbara Beci³, Martina Klinkon, \\ Marija Nemec ${ }^{1}$, Jaka Jakob Hodnik ${ }^{1}$, Jože Starič ${ }^{1}$ \\ ${ }^{1}$ Clinic for Reproduction and Large Animals, Veterinary Faculty, University of Ljubljana, Kongresni trg 12, 1000 \\ Ljubljana, Slovenia \\ ${ }^{2}$ Fishguard veterinary services, Trem Y Mor, Fishguard SA65 9DW, Pembrokeshire, Wales, UK \\ ${ }^{3}$ DAP de Linde Retie, Noordstraat 73, 2470 Retie, Belgium
}

To link to this article: https://doi.org/10.11118/actaun201967051147

Received: 1. 7. 2019, Accepted: 20. 8. 2019

To cite this article: JEŽEK JOŽICA, GRABNAR PETRA, BECI BARBARA, KLINKON MARTINA, NEMEC MARIJA, HODNIK JAKA JAKOB, STARIČ JOŽE. 2019. Management Practices Affecting Calves Welfare on Farms in Slovenia. Acta Universitatis Agriculturae et Silviculturae Mendelianae Brunensis, 67(5): 1147-1152.

\begin{abstract}
Calf rearing practices in Slovenian herds were investigated with questionnaire-based survey. The data was obtained from 293 farms in Slovenia about their management, especially milk and colostrum feeding protocol, manner of weaning, housing, hygiene on the farm and biosecurity measures. Majority of respondents think the colostrum supply is very important. In $77 \%$ of farms, calves receive the first colostrum meal within 2 hours after birth. Quality of colostrum is not considered in $59 \%$ of farms. The temperature of colostrum and milk check $73 \%$ of farmers, however majority do it manually without using thermometer. Farmers weans calves gradually, mostly considering the age at weaning (45\%). Calves are weaned at mean age of 14.18 weeks. In $57.3 \%$ of farms, newborn calves are housed in individual pens. Thirty four percent of farmers are cleaning pens for newborn calves after each calf. Half of farmers observe their calves more than 15 minutes daily. Different biosecurity measures are used in $98 \%$ of farms. Many farmers are well aware that calf rearing management bear on later milk and meat production and some would need more persuasion to follow the appropriate management practices.
\end{abstract}

Keywords: welfare, management, colostrum, weaning, housing, biosecurity, calf

\section{INTRODUCTION}

Calves health is of key importance for the future high milk and meat production. There is also high public interest in farm animal welfare. Good management practices are essential for calves health and wellbeing. Calves health and welfare depends on various factors (colostrum supply, rearing conditions...) and there are differences between herds (Moran, 2002; Svensson et al., 2003; Vasseur et al., 2010a). Surveys on calf rearing found that farmers use management practices that place calf health at risk and negatively influence calf welfare. These include infrequent use of calving pen and surveillance of calvings, inadequate colostrum supply, not checking colostrum quality and feeding waste milk to the calves (Vasseur et al., 2010a; Klein-Jöbstl et al., 2015). Calf management has been evaluated in several countries in Europe and in North America with larger cattle herds (Vasseur et al., 2010a; Seppä-Lassila et al., 2016; Santman-Berends et al., 2014). Cattle holdings in Slovenia are traditionally family-owned and small sized with an average number of 14.8 cattle (Sadar et al., 2018). Calf management practices on small sized farms may be different than in countries where large farms predominate. Differences in calf management between small and large farms were found in Austria (Klein-Jöbstl et al., 2015). 
To evaluate the risks for calf health and welfare the most commonly used management practices that may be a hazard for animals should be identified. Voluntary improvements in animal welfare can be facilitated by using appropriate tools to educate producers and help them change their attitudes toward calf management and animal welfare (Vasseur et al., 2010b)

Purpose of this study was to obtain data from different farms in Slovenia about their calf rearing practices that may affect animal health and welfare.

\section{MATERIALS AND METHODS}

A questionnaire was designed to investigate calfrearing practices. The farms $(n=293)$ from different regions in Slovenia participated the survey. We gathered data with on-line questionnaire (www.1ka.si) and directly with questionnaires that were given or send to farmers. Participating in survey was voluntary and anonymous. Frequencies were calculated with statistical programme R used by internet page mentioned above.

\section{RESULTS}

Of 293 farmers surveyed 49\% were engaged in milk production, the rest were oriented in beef production.

In area of milk and feeding protocol, we have been interested in farmers' opinion about importance of colostrum for newborn calf (Fig. 1).
Upon asking when their calves receive the first colostrum, 77\% answered within 2 hours after birth. According to our results calves received at the average $2.06 \mathrm{~L}$ colostrum at first feeding. The farmers had the chance to answer weather they consider the quality of colostrum. Quality of colostrum is not considered in 59\% of farms. Farmers who consider the quality of colostrum avoid the use of visually inappropriate colostrum or colostrum from cows with mastitis.

The temperature of colostrum and milk is checked by $73 \%$ of respondents but most of them do it by hand (67\%) without using thermometer. Eighty four percent of farmers clean milk-feeding containers after each use. On $41 \%$ of farms calves has access to water at the age of 8-14 days.

The majority of farmers (84\%) wean calves gradually according to various criteria (age, body weight, daily intake of concentrate). Most of them consider the age at weaning (45\%). Calves are weaned at the mean age of 14.18 (SD 6.82) weeks. The large variation appear because the survey includes farms of milk and meat production. Meat producers mostly wean calves much later than milk producers what influenced the results. Sixty seven percent of farmers reported that they execute gradual weaning by gradually diminishing the amount of milk per meal.

In $57.3 \%$ of farms, newborn calves are housed in individual pens. Average area per calf in pen in

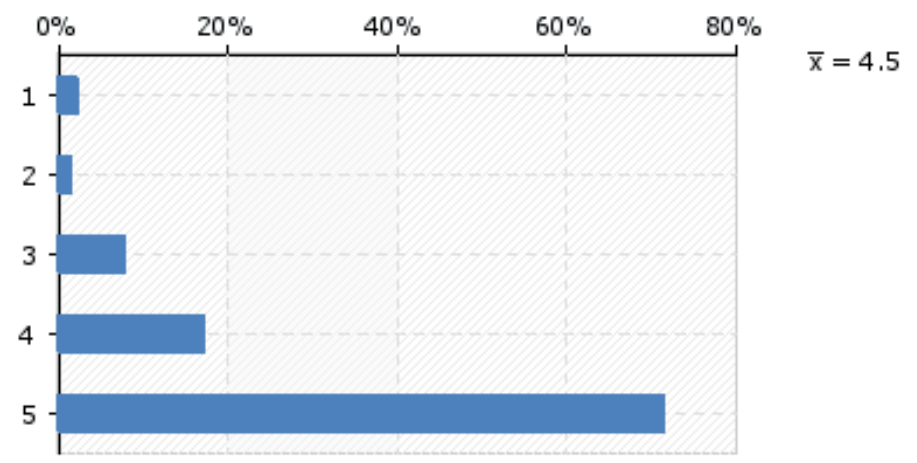

1: The meaning of colostrum supply for newborn calf (1 means no importance and 5 means most important)

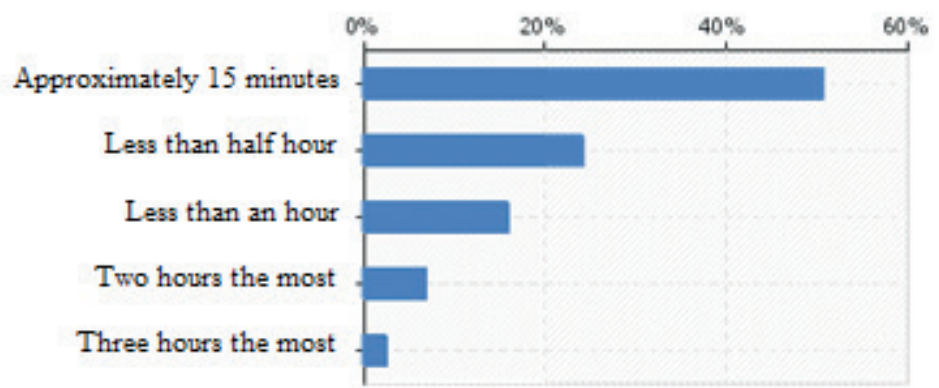

2: Time used for calf observation (percentage of farms) 
Slovenian farms is 2.9 (SD 1.57) $\mathrm{m}^{2}$; however, 21\% farmers in our study use smaller pens.

Thirty four percent of farmers clean pens for newborn calves after each calf and 13\% after each sick calf. Eighteen percent of farmers who clean pens also use disinfectants. The rest of farmers very rarely or never clean the pens.

Half of farmers observe their calves more than 15 minutes daily. Fig. 2 present time used for calf observation.

Farmers apply various biosecurity measures on the farms (exterminate flies, rodents, disinfection barrier at the entrance, no other animal species (pigs, poultry) housed in cattle barn). At least one of biosecurity measures is used in $98 \%$ of farms; most often, they exterminate flies and rodents.

\section{DISCUSSION}

Because of anonymous nature of questionnaire and voluntary participation, we suppose answers were in great majority honest.

Calving management and care of the newborn are important for the calves' health (KleinJöbstl et al., 2015). The most important factor for preventing illness and mortality of newborn calves is feeding colostrum of good quality, at proper time and in proper volume (Godden, 2008). The results of this study regarding colostrum supply are encouraging showing that farmers are well aware of importance of feeding colostrum. Because of this, they can improve management and enhance production. The immune system of calves is completely developed at birth but it does not function on the level of adult animals what makes the calves more susceptible to infections in the first weeks of life (Tizard, 2004). The passive transfer of colostral immunoglobulins from dam to newborn is the most effective way for protection against infectious diseases immediately after birth (Uetake, 2013). It is crucial that calves received colostrum within 1-2 hours or not later than in 6 hours after birth (Godden, 2008). The results of this study have shown that most farmers work in accordance with these recommendations. The efficiency of immunoglobulin absorption is 50\% 6 hours after parturition, 33\% after 8 hours and after 24 hours there is almost no absorption (Godden, 2008). Rajala and Castren (1995) found that delay of colostrum intake for each 30 minutes decreases calf serum immunoglobulin concentration for $2 \mathrm{~g} / \mathrm{L}$.

It is recommended that calves receive at least $10-12 \%$ of body weight of colostrum in the first 12 hours after birth (Godden, 2008). According to our results calves received at the average $2 \mathrm{~L}$ of colostrum at the first meal. When they received 2 to 3 meals in the first 12 hours this recommendation is followed on most of farms.

Several factors may influence quality of colostrum (Godden, 2008) and quality of colostrum influences importantly efficiency of colostral immunity. Our results revealed that less than half of farmers consider quality of colostrum what may be a risk factor for failure of passive transfer and higher morbidity in calves. Similar was found in study performed in Austria, where most farmers (97.2\%) did not check first colostrum quality by use of hydrometer (Klein-Jöbstl et al., 2015). It is possible that farmers are not aware on importance of colostrum quality.

Our results indicate that farmers pay too little attention to ensuring adequate milk temperature for feeding calves. Most of them check the temperature of milk only by hand. Fifty nine percent of farmers reheat milk or colostrum before feeding. Appropriate temperature of milk fed to the calves is important because to low temperature of milk impair digestion in abomasum (Mornet and Espinasse, 1990) and may cause diarrhoea.

Most of respondents claim they clean milk-feeding containers after each use. This indicates most farmers are aware of fact that feeding containers are most likely source of infections because they are ideal place for bacterial growth. Cleaning and disinfecting of entire feeding equipment after each use would be most appropriate (Moran, 2002).

Water is an essential nutrient so satiation of thirst is one of the basic needs of animals. According to welfare principles, an animal should have a free access to sufficient quantity of drinking water. Provision of drinking water immediately after birth could improve growth and development of calves pre- and post-weaning, potentially by stimulating rumen development, thus increasing nutrient availability (Wickramasinghe et al., 2019). Results of this study revealed that on $41 \%$ of farms calves have access to water at the age of 2 weeks. In Austrian study on $71.5 \%$ of farms, calves had access to water at the age of 1-3 weeks (Klein-Jöbstl et al., 2015). Results indicate that many farmers are not following recommendation regarding water provision.

Weaning off milk is the first major feeding transition for calves and is particularly stressful for the animal and challenging for the producer (Vasseur et al., 2010a). It is considered that natural weaning in meet breeds is at 7 months of age (Waterman et al., 2012). Allen (2004) believes due to economic reasons the best time for weaning is between $5^{\text {th }}$ and $7^{\text {th }}$ week of age. In southern Brazil, dairy calves are weaned at the average age of 82 days (Hötzel et al., 2014). Moran (2002) suggests at weaning calves should have at least $70 \mathrm{~kg}$ of body weight, developed rumination and are able to consume $0.5 \mathrm{~kg}$ concentrates daily. Andrews (2004) observed in calves weaned at 5 weeks more lung lesions comparing to calves fed ad-libitum up to 14 weeks. Reasons for that could be lower energy input, smaller amount of micronutrients in the fodder and stress at weaning. The mortality risk of calves aged 7-180 days was higher in 
farms with a shorter milk-feeding period (SeppäLassila et al., 2016). Allen (2004) recommends the amount of milk should be gradually diminished through 5 to 10 days. According to de Passillé et al. (2011) gradually weaning enhances the amount of consumed starter. Our respondents claim that on most of farms calves are weaned gradually, at the average age of 14 weeks, which is an encouraging result in the light of the above recommendations.

Calf housing is one of important calf welfare issues. On more than half of participating farms, newborn calves are housed in individual pens. Individual calf housing is common in many countries (Klein-Jöbstl et al., 2015; Hötzel et al., 2014). The advantage of individual housing is reduced transmission of diseases and easier surveillance of calves. Observing, examination and treatment of calves are handier in individual pens (Hepola, 2003). Average area per calf in pen in most of farms is in agreement with prescribed standards (Council directive 2008/119/EC of 18 December 2008): at least $1.5 \mathrm{~m}^{2}$ per calf till $150 \mathrm{~kg}$ of body weight. However, 21\% farmers in our study use smaller pens.

According to standards of Council directive 2008/119/EC of 18 December 2008 group housing is compulsory for calves older than 8 weeks with exception of calves health or behaviour alterations. Directive was followed on majority of participating farms. The benefits of group housing are increased opportunities for social interactions, and greater access to space, which facilitates physical exercise and allows more normal behaviour (Vasseur et al., 2010a). Increasing the level of social contact in the home environment made calves less fearful in novel social and environmental situations and improves calves welfare. Type of housing (individual vs. pair) did not affect clinical scores and health of the calves (Jensen and Larsen, 2014).

Housing of calves and hygiene of environment is one of the most important factors in epidemiology of infectious diseases (Sanders, 1985). Calf sheds should be built in ways that allow easy cleaning and maintenance of hygienic conditions (Moran, 2002). Appropriate hygiene of delivery pens is of paramount importance for prevention of colisepticaemia, rotavirus infection and omphalophlebitis in newborn calf (Van Metre, et al., 2008; Mee, 2008). Inadequate cleaning and disinfection of pens prior to housing a new calf increases frequency of gastrointestinal and respiratory diseases (Andrews, 2004; Van Metre, et al., 2008). Farmer's responses in our study indicate that they do not attach much importance to cleaning of pens for newborn calves after each calf. Unlike the Austrian study where more than half of farmers clean the calf housing area regularly not only dry but also with high pressure cleaner (KleinJöbstl et al., 2015). The percentage of farmers who additionally use disinfectants was similar in both countries.

Regular observing of animals is very important for successful rearing. Time saved on account of automation should be used for observation of animals and cleaning of milk-feeding equipment (Hepola, 2003). Our results indicate that farmers observe their calves at least 15 minutes daily.

Biosecurity measures are important to prevent introduction and spreading of infectious diseases on the farm. Almost all respondents use at least one biosecurity measure, most often they exterminate flies and rodents but only exceptionally they use quarantine for newly purchased animals.

\section{CONCLUSION}

Farmers are well aware of importance of appropriate colostrum supply for the calves' health. Less attention is dedicated to the colostrum quality, temperature of milk fed to the calves and water provision. In most farms calves are weaned gradually with diminishing the amount of milk per meal. Area per calf in pen is in majority of farms adequate. Cleaning of milk feeding equipment is common but thorough cleaning of pens for newborn calves is rare. At least one of biosecurity measures is used on the farms.

It is obvious that many farmers are well aware that calf rearing management bear on later milk and meat production and some would need more persuasion to follow the appropriate management. We think this would improve production, welfare and health of calves.

\section{Acknowledgements}

We acknowledge all the farmers who participated in the survey and veterinarians who helped by distribution of the questionnaires. The authors acknowledge the financial support from the Slovenian Research Agency (research core funding No. [P4-0092]). 


\section{REFERENCES}

ALLEN, D. M. 2004. Calf Rearing. In: ANDREWS, A. H. et al. (Ed.). Bovine Medicine: Diseases and Husbandry of Cattle. $2^{\text {nd }}$ Edition. Oxford: Blackwell Science, pp. 3-6.

ANDREWS, A. H. 2004. Calf Respiratory Disease. In: ANDREWS, A. H. et al. (Ed.). Bovine Medicine: Diseases and Husbandry of Cattle. $2^{\text {nd }}$ Edition. Oxford: Blackwell Science, pp. 239-248.

DE PASSILLÉ, A. M., BORDERAS, T. F. and RUSHEN, J. 2011. Weaning age of calves fed a high milk allowance by automated feeders: Effects on feed, water, and energy intake, behavioural signs of hunger, and weight gains. J. Dairy Sci., 94(3): 1401-1408.

THE COUNCIL OF THE EUROPEAN UNION. 2008. Council directive 2008/119/EC: Laying down minimum standards for the protection of calves. Available at: http://eur-lex.europa.eu/legal-content/EN/TXT/ PDF/?uri=CELEX:32008L0119\&from=EN [Accessed: 17.6.2019].

GODDEN, S. 2008. Colostrum Management for Dairy Calves. Vet. Clin. North Am.: Food Anim. Pract., 24(1): 19-39.

HEPOLA, H. 2003. Milk feeding systems for dairy calves in groups: effects on feed intake, growth and health. Appl. Anim. Behav. Sci., 80(3): 233-243.

HÖTZEL, M. J., LONGO, C., BALCAO, L. F., CARDOSO, C. S. and COSTA, J. H. C. 2014. A survey of management practices that influence performance and welfare of dairy calves reared in southern Brazil. PLOS ONE, 9(12): e114995.

JENSEN, M. B. and LARSEN, L. E. 2014. Effect of level of social contact on dairy calf behavior and health. J. Dairy Sci., 97: 5035-5044.

KLEIN-JÖBSTL, D., ARNHOLDT, T., STURMLECHNER, F., IWERSEN, M. and DRILLICH, M. 2015. Results of an online questionnaire to survey calf management practices on dairy cattle breeding farms in Austria and to estimate differences in disease incidences depending on farm structure and management practices. Acta Vet. Scand., 57: 44.

MEE, J. F. 2008. Newborn Dairy Calf Management. Vet. Clin. North Am.: Food Anim. Pract., 24(1): 1-17.

MORAN, J. 2002. Calf Rearing: A practical Guide. $2^{\text {nd }}$ Edition. Collingwood Vic, Australia: Landlinks Press.

MORNET, P. and ESPINASSE, J. 1990. Das Kalb. Hengersberg, Germany: Schober Verlag.

RAJALA, P. and CASTREN, H. 1995. Serum immunoglobulin concentrations and health of dairy calves in two management systems from birth to 12 weeks of age. J. Dairy Sci., 78: 2737-2744.

SADAR, M., JENKO, J., JERETINA, J., LOGAR, B., OPARA, A. and PERPAR, T. 2018. Results of Dairy and Beef recording Slovenia 2017 [in Slovene: Rezultati kontrole prireje mleka in mesa Slovenija 2017]. Ljubljana, Slovenia: Kmetijski inštitut Slovenije.

SANDERS, D .E. 1985. Field management of neonatal diarrhea. Vet. Clin. North Am.: Food Anim. Pract., 1(3): 621-637.

SANTMAN-BERENDS, I. M. G. A., BUDDIGER, M., SMOLENAARS, A. J. G., STEUTEN, C. D. M., ROOS, C. A. J., VAN ERP, A. J. M. and VAN SCHAIK, G. 2014. A multidisciplinary approach to determine factors associated with calf rearing practices and calf mortality in dairy herds. Prev. Vet. Med., 117: 375387.

SEPPÄ-LASSILA, L., SARJOKARI, K., HOVINEN, M., SOVERI, T. and NORRING, M. 2016. Management factors associated with mortality of dairy calves in Finland: A cross sectional study. Vet. J., 216: 164-167.

SVENSSON, C., LUNDBORG, K., EMANUELSON, V. and OLSSON, S. O. 2003. Morbidity in Swedish dairy calves from birth to 90 days of age and individual calf-level risk factors for infectious diseases. Prev. Vet. Med., 58(3-4): 179-197.

TIZARD, I. 2004. Veterinary immunology. $6^{\text {th }}$ Edition. Philadelphia, USA: W.B. Saunders company.

UETAKE, K. 2013. Newborn calf welfare: A review focusing on mortality rates. Anim. Sci. J., 84(2): 101-105.

VAN METRE, D. C. et al. 2008. Chapter 6 - Infectious Diseases of the Gastrointestinal Tract. In: DIVERS T. J. and PEEK, S. F. (Eds.). Rebhun's Diseases of Dairy Cattle. $2^{\text {nd }}$ Edition. St. Louise, Missouri, USA: Saunders Elsevier, pp. 200-294.

VASSEUR, E., BORDERAS, F., CUE, R. I., LEFEBVRE, D., PELLERIN, D., RUSHEN, J., WADE, K. M. and DE PASILLE, A. M. 2010a. A survey of dairy calf management practices in Canada that affect animal welfare. J. Dairy Sci., 93: 1307-1315.

VASSEUR, E., RUSHEN, J., DE PASSILLE, A. M., LEFEBVRE, D. and PELLERIN, D. 2010b. An advisory tool to improve management practices affecting calf and heifer welfare on dairy farms. J. Dairy Sci., 93: 4414-4426.

WATERMAN, R. C., GEARY, T. W., PATERSON, J. A. and LIPSEY, R. J. 2012. Early weaning in Northern Great Plains beef cattle production systems: I. Performance and reproductive response in range beef cows. Livestock Sci., 148(1-2): 26-35. 
WICKRAMASINGHE, H. K. J. P., KRAMER, A. J. and APPUHAMY, J. A. D. R. N. 2019. Drinking water intake of newborn dairy calves and its effects on feed intake, growth performance, health status, and nutrient digestibility. J. Dairy Sci., 102: 377-387.

Jožica Ježek: jozica.jezek@vf.uni-lj.si Petra Grabnar: petra.grabnar@gmail.com Barbara Beci: Barbara.beci@gmail.com Martina Klinkon: martina.klinkon@vf.uni-lj.si Marija Nemec: marija.nemec@vf.uni-lj.si Jaka Jakob Hodnik: jaka.hodnik@vf.uni-lj.si Jože Starič: joze.staric@vf.uni-lj.si 